\title{
Prognosis of anomalous coronary arteries originating from the opposite sinus of Valsalva (ACAOS): 15 year experience from two large CMR centres
}

\author{
David P Ripley ${ }^{1,2^{*}}$, Albert Teis ${ }^{3}$, Akhlaque Uddin ${ }^{1,2}$, Petra Bijsterveld ${ }^{1}$, Ansuman Saha ${ }^{1}$, Ananth Kidambi ${ }^{1,2}$, \\ Bernhard A Herzog ${ }^{1,2}$, Sven Plein ${ }^{1,2}$, Dudley J Pennell ${ }^{3}$, John P Greenwood ${ }^{1,2}$
}

From 16th Annual SCMR Scientific Sessions

San Francisco, CA, USA. 31 January - 3 February 2013

\section{Background}

Aberrant coronary arteries represent a diverse group of congenital disorders, many of which may have no clinical significance. Post mortem studies show a high risk of exercise related sudden cardiac death in those with an anomalous coronary artery originating from the opposite sinus of Valsalva (ACAOS) that takes an interarterial (anterior) course. However, there is little documentation in life of the long term natural history of anomalous coronary arteries.

\section{Methods}

Databases from two cardiovascular magnetic resonance (CMR) centres (Leeds General Infirmary and Royal Brompton Hospital) were reviewed. Patients with anomalous coronary arteries undergoing CMR over a 15 year period (1995 to 2009) were identified. Anomalous coronary arteries were classified according to their anatomy and course. Both the electronic and paper records of all patients were reviewed for major adverse cardiovascular events (MACE) defined as cardiovascular mortality, myocardial infarction, revascularisation (PCI or CABG). Cause of death was verified by the Office for National Statistics. Revascularisation or myocardial infarctions were only counted if they occurred in the distribution of the anomalous artery.

'Multidisciplinary Cardiovascular Research Centre (MCRC) \& Leeds Institute of Genetics, Health and Therapeutics, University of Leeds, Leeds, UK

Full list of author information is available at the end of the article

\section{Results}

173 consecutive patients with coronary artery anomalies were retrospectively identified with a median age 54 years (range 1-85). The median follow-up time was 4.3 years (IQR 2.5 - 7.8) with a maximum of 15.6 years. Of the 173 patients, 117 had ACAOS of which 111 were alive, 5 deceased and 1 lost to follow-up. 65 patients (56\%) had an inter-arterial course and $52(44 \%)$ a posterior course. The distribution of coronary anomalies is detailed in Table 1.

In those patients with ACAOS there were 59 MACE events (5 cardiovascular deaths, 6 PCI, 24 CABG and 24 had myocardial infarction). 48 MACE events occurred in ACAOS with an anterior course and 11 with a posterior course $(\mathrm{p}<0.0001)$ the statistical difference driven by surgical revascularisation and myocardial infarction (Table 2).

\section{Conclusions}

We have demonstrated that in life, patients with an anomalous coronary artery originating from the opposite sinus of Valsalva taking an anterior course, have higher rates of both myocardial infarction and surgical revascularisation during long-term follow up, compared to those with a posterior course.

\section{Funding}

S.P is funded by a British Heart Foundation fellowship (Fs/10/62/28409) S.P. and J.P.G received an educational research grant from Philips Healthcare.

C 2013 Ripley et al; licensee BioMed Central Ltd. This is an Open Access article distributed under the terms of the Creative Commons 
Table 1 Classification of anomalous coronary arteries $(n=173)$

\begin{tabular}{|c|c|}
\hline Classification & Number \\
\hline \multicolumn{2}{|l|}{ 1. Origin of both RCA and LMS (separate origins) from the right aortic sinus } \\
\hline - 1a. Course of anomalous LMS between aorta and RVOT (anterior) & 13 \\
\hline - 1b. Course of anomalous LMS not between aorta and RVOT (posterior) & 8 \\
\hline \multicolumn{2}{|l|}{ 2. Origin of both coronary arteries (separate origins) from the left aortic sinus } \\
\hline - 2a. Course of anomalous RCA between aorta and RVOT (anterior) & 34 \\
\hline - 2b. Course of anomalous RCA not between aorta and RVOT (posterior & 0 \\
\hline \multicolumn{2}{|l|}{ 3. Anomalous origin of the circumflex coronary artery from the right aortic sinus } \\
\hline - 3a. Course of anomalous LCX between aorta and RVOT (anterior) & 1 \\
\hline - 3b. Course of anomalous LCx not between aorta and RVOT (posterior) & 33 \\
\hline \multicolumn{2}{|l|}{ 4. Anomalous origin of the left anterior descending artery from the right aortic sinus } \\
\hline - 4a. Course of anomalous LAD between aorta and RVOT (anterior) & 4 \\
\hline - 4b. Course of anomalous LAD not between aorta and RVOT (posterior) & 6 \\
\hline \multicolumn{2}{|l|}{ 5. Single coronary artery (common origin) } \\
\hline - 5a. Course of anomalous coronary artery between aorta and RVOT (anterior) & 13 \\
\hline - 5b. Course of anomalous coronary artery not between aorta and RVOT (posterior) & 5 \\
\hline \multicolumn{2}{|c|}{ 6. Anomalous origin or communication of a coronary artery with a cardiac chamber or major thoracic vessel } \\
\hline - 6a. Abnormal origin from the pulmonary artery or one of its major arterial branches & 11 \\
\hline - 6b. Abnormal origin from the aorta or one of its major arterial branches & 2 \\
\hline - 6c. Abnormal communication of a coronary artery with a cardiac chamber or major thoracic vessel (fistula). & 18 \\
\hline 7. Miscellaneous / unclassified & 25 \\
\hline
\end{tabular}

Table 2 Major Adverse Cardiovascular Events in patients with an anomalous coronary artery originating from the opposite sinus of Valsalva (ACAOS) $(n=117)$

\begin{tabular}{cccc}
\hline & Anterior $(\mathrm{n}=65)$ & Posterior $(\mathrm{n}=52)$ \\
\hline Cardiovascular Deaths, $\mathrm{P}$ & 3 & 2 & $\mathrm{~N}$ value \\
\hline $\mathrm{PCl}, \mathrm{n}$ & 4 & 2 & $\mathrm{NS}$ \\
\hline Surgical revascularisation, $\mathrm{n}$ & 23 & $\mathrm{P}<0.0001$ & $\mathrm{P}<0.05$ \\
\hline Myocardial Infarction, $\mathrm{n}$ & 18 & \\
\hline
\end{tabular}

\section{Author details}

${ }^{1}$ Multidisciplinary Cardiovascular Research Centre (MCRC) \& Leeds Institute of Genetics, Health and Therapeutics, University of Leeds, Leeds, UK. ${ }^{2}$ Leeds

General Infirmary, Leeds Teaching Hospitals NHS Trust, Leeds, UK.

${ }^{3}$ Cardiovascular Magnetic Resonance Unit, Royal Brompton Hospital, London, UK.

Published: 30 January 2013

doi:10.1186/1532-429X-15-S1-P257

Cite this article as: Ripley et al:: Prognosis of anomalous coronary arteries originating from the opposite sinus of Valsalva (ACAOS): 15

year experience from two large CMR centres. Journal of Cardiovascular Magnetic Resonance 2013 15(Suppl 1):P257.
Submit your next manuscript to BioMed Central and take full advantage of:

- Convenient online submission

- Thorough peer review

- No space constraints or color figure charges

- Immediate publication on acceptance

- Inclusion in PubMed, CAS, Scopus and Google Scholar

- Research which is freely available for redistribution

Submit your manuscript at www.biomedcentral.com/submit 